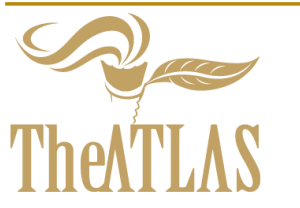

\title{
From a Disciplinary to a Transdisciplinary Vision of the University: A Space of Knowledge, Culture, Art, Spirituality, and Life
}

\author{
Domingo Adame, Universidad Veracruzana, Facultad de Teatro Xalapa, Veracruz, México, Email: \\ domingoadame@yahoo.com
}

doi: $10.22545 / 2011 / 00018$

I ow does one understand the University situation today? Is the disciplinary paradigm viable? What are the consequences of this paradigm? In my paper, I give one answer to these questions and review, from my own academic experience in a Mexican University (Veracruzana University), strategies like Complex Thought (Edgar Morin) and Transdisciplinarity (Basarab Nicolescu) to affirm the urgency of moving from a one-disciplinary vision to another-transdisciplinary. I maintain that only with this change will the University, especially in Latin-America, be able to offer an integral education in which both professors and students may solve real world problems effectively and affectively. Only in this way will the University contribute to a genuine social transformation.

Keywords: disciplinary, transdisciplinary, complex thought, effectivity, affectivity.

\section{Introduction}

Current State of the University How does one define todays University? Is there only one kind of University? The first problem is that there is not only one definition for the current University; its essence, or universality, has stopped being operational in a world where transformations come at an increasingly intense speed with social and political problems ever more acute.

There are also large disparities between universities of the north and those of the south and between public and private universities. For example, there are abysmal differences between the National Autonomous University of Mexico or the University of Sao Paulo in Brazil and the National University of El Salvador in Central America. It cannot be denied that characteristics of every society determine its own style of education, yet the dominant paradigms are still imposing their educational practices.

The University, a very classic and traditional institution with more than nine centuries of existence, faces dizzying changes marked by globalization, cultural diversity, and information and communication technologies. This situation occurs within the frame of inequality.

In light of this environment, it is necessary to ask if the University is currently satisfying the necessities of society and of promoting creativity by means of the transmission and generation of knowledge. In this sense, the question is: does humanity today live 
better than before thanks to the University?

It is difficult to know what part of society's achievements are a result of the University's action while at the same time what share of responsibility the University has had in the big failures, but undoubtedly it takes part in both. Certainly, the human potential locked in the University has not been sufficiently tapped into, especially due to its rigid institutional structure and its uncritical response to external demands. So, its crises have its origins both from within and from with out.

\section{The Crises of the University}

The Portuguese academic Boaventura de Souza did an analysis of the situation of the public university, in particular in Brazil. The analysis indicates that there are three crises: one of hegemony, due to the contradictions between the traditional functions and those who in the 20th century were attributed to it; another of legitimacy, for the fact that it stopped being an institution consensual, opposite to the contradiction of the hierarchical organization of specialized knowledges and to the social and political requirements of democratization and equality of opportunities; and an institutional crisis, for the contradiction between recovery of autonomy and the increasing pressure for submitting it to criteria of efficiency and productivity of managerial character or social responsibility [1].

The epistemic state of the University and its social function is, today more than ever, antagonistic. Thus, one comes to recognize the need for transformation in Latin America. The globalizing and neo-liberal perspective that promotes expansion of the educational market sought to impose a managerial paradigm that led the marketing of the University. This stimulated the creation of the university market.

As a consequence, the problems grew. For instance, we saw the unprecedented acceleration of the fragmentation of knowledge, a rejection of sharing knowledge, a lack of tolerance, and a separation of science and culture (the origin of which goes back at least three centuries ago).

Media culture displaced to a great extent the academic culture. Teachers turned into objects of evaluation. Efficiency has arisen to the detriment of creativity and open thought. In sum, "universities follow the mandates of a lone simplistic, professionalizing and enterprising culture of education" [2].
Opposite of this vision, one began to speak from the academic field of changing mentality and institutional structure and of orientating the University toward the sustainability. It is precisely from this approach that we encounter two questions: how can the University respond to the challenges of the 21st century? What reforms does the University need in order to offer an integral and open formation that links effectivity and affectivity, which connects the university student with the complexity of the world, which contributes to the genuine social transformation, and which gives a place for culture, art, spirituality, and life in the university?

An extremely reductionist thinking has raised the possibility of "closing the university if it does not answer to its raison d'ětre." If its raison d'ětre is the generation of knowledge, it is practically impossible that this happen. However, if one goes along with the global and neo-liberal vision of turning the university into a market of credits, then inevitably it will have to disappear to make way for a new organization based on the integral and creative formation, spiritual autonomy, and a connection with society of the student.

We must not forget, as well Edgar Morin and Basarab Nicolescu remind us, that at present the risk is the destruction of our planet and, in consequence, of humanity. For this reason, the University must respond at the same level as the present circumstances.

\section{The Disciplinary University}

The disciplinary fragmentation and the division of systemic problems maintain a theoretical superficiality, strongly conditioning the social development of countries.

The disciplinary organization has a correlate in the genesis of the modern universities in the 19th century. In this respect, the disciplines have a historic development that is ingrained in the history of society, but in addition it possesses an epistemological and paradigmatic dimension similar to the understanding of the ways of organizing disciplinary knowledge and their processes of closing and opening.

The notion of discipline, in this context, can be defined as an organizing category inside the scientific knowledge, instituting division and specialization. The organization of the knowledge into many disci- 
plines has stimulated separate models, increasingly preventing the methodological and epistemological integration.

University knowledge has been predominantly disciplinary "whose autonomy imposed a process of relatively decontextualized production in relation to the daily needs of society. Following the logic of this process, the researchers determined the scientific problems to resolve, defining its relevancy and establishing the methodologies and the rhythms of inquiry ... The University produces knowledge that society can apply or not, an alternative that, as socially relevant as it, may be indifferent or irrelevant for the produced knowledge" (Boaventura, 2010, p. 41) $[1]$.

\section{Alternatives to the Disciplinary Paradigm}

For example in Brazil, Ubiratan de Ambosio has raised the urgency of new models or a different way of facing life with a new organization of the University. He proposed a transdisciplinary approach for a real change in the essence of the humanity [3].

In effect, throughout the 20th century, a new way of seeing and understanding the world was generated that instigated the rupture of former shared convictions, concepts, techniques, and values supported and used by scientific communities. A new epistemology emerged with the General Theory of Systems, Cybernetics, Constructivism and Constructionism, Sciences of Cognition and later Complex Thought and Transdisciplinarity that opened the possibility of co-generating a more dynamic conception of the human being and a new way of understanding reality and knowledge itself [4].

This nascent epistemology started by generating a new way of "knowing our knowing" [5]. What in the paradigm of modernity was translated as an anomaly, a contradiction, and a sign of mistaken thought, in this different perspective appears as a crisis, a fork in the road, a possibility of new ways.

For example, the unidirectional reason/effect was confronted with the circularity that proposes a recursive effect. In this way, the knowledge that the University generates must regenerate the knowledge that the University offers. A University that does not recognize the biodegradability of knowledge cannot affirm that it generates knowledge. It is not a question of changing what it is necessary to know, since it is always dynamic, but the way of knowing. The concept of feedback arises as a unit of interaction in a system where the observer is a subjective participant, a co-participator in the process that before was made separate in an effort to be objective.

The situation of a change for the University offers to all its members the possibility of placing themselves within the change itself and invites others to actively involve themselves in this construction of doing while doing.

Little by little, from this position, the knowledge is traveling between interactions and cognitions that are mutually influenced.

Between a globalization that socially homogenizes and a fragmentation that mutilates education, an intermediate zone emerges, which is only possible to conceive from a complex and transdisciplinary perspective of constructing the University.

\section{Transdisciplinary Vision of the University}

New looks to address and to transform the role of the University in the contemporary societies have appeared from different areas for many decades. As much from the social, political, cultural, and economic point of view as from the perspective of the increasing complexity of the real world, the function of the knowledge is key in terms of transformation and in terms of citizenship and social responsibility.

The University, as an institution that produces knowledge and forms opinion and trends, has an unquestionable social responsibility. Its priority task today should be regarding thought itself - elucidating the conditions that construct knowledge, that form professionals that conceive the human condition to know and act. From this perspective, the University has an urgent task: determining the why, how and what to know.

The hyper-specialization and compartmentalization of disciplines prevent access to broader and related knowledge. That is the reason why the single disciplinary education is becoming increasingly inadequate and why there must be cooperation between disciplines, among the various center of culture and knowledge, among different knowledges (scientific, artistic, and techniques). Under compartmentalization, teachers and university researchers are interested only in the skills they need to excel in their field. Research and education in science, literature, philosophy, and human sciences generally respond to criteria of technical efficiency and profitability 
without offering a critical view of knowledge, a prerequisite for making necessary distance and to give meaning to the task of knowledge.

The University, as a space where knowledge is generated and processed, cannot fail to look at itself critically to detect its own stagnation. It is necessary to recover its ability to regenerate to avoid higher risk: mental and emotional stagnation of new generations.

Isolated academic disciplines are less than adequate to deal with wider personal and social problems. The fragmentation of the disciplines leads to passivity and, at its best, answers only one part of what social life demands: that we were trained by a single discipline.

While knowledge does not provide the all the necessary means to contend with the complexity of reality, it does increase the expression of our human potential.

That complex reality is not only that of work and daily subsistence, nor the world television programs present, nor financial markets, nor that of the corrupt dictatorship or pseudo-democratic governments, nor the savage crimes that occur daily; on the contrary, the complex reality is also that of the tiny acts of courage, solidarity, affectivity, creativity, spirituality, and all that is infinitely small or infinitely large that escape our senses.

How can science and scientific research, arts and its practices, technical and traditional knowledge-all of them products of intelligence and imagination of humankind-be available and beneficial for society?

If the purpose of university culture is the elevation of spirit, achieving this requires linking all the knowledge and recognizing that only from the human dimension will the University serve humankind. For a better understanding of the world, the University must overcome the radical disjunction of knowledge across disciplines and establish a bridge between them. The University in the 21st century should prepare persons that can be placed between, across, and beyond their discipline, their culture, their nation, their politics, and their religion.

\section{Complexity and Transdisciplinarity}

The paradigm of complexity designed by Edgar Morin and transdisciplinarity methodology proposed by Basarab Nicolescu constitute a relevant pathway for the transformation of the University.

We take of the complex thought-the opposite of the simplified thought - the multidimensional relationship between man, society, life, and the world. The complexity is relevant because it suggests the invention against repetition. This is a new strategy that faces the challenge of real world. Edgar Morin proposed a method that consists of three principles: dialogic, recursive, and hologramatic [6].

Complex thought questions the validity of teaching knowledge without teaching what it means to know. Perhaps as never before, complex thought requires an ethical and strategic purpose. Morin, on the occasion of a dialogue on the relationship between ethics and development, emphasized that:

"We must also change the structure of the education system, because development brings a conception of expertise of each person, and each person is dedicated in their particular corner and forgets the responsibility of solidarity with the whole. If we change the structure of education, no more specialization, but we raised fundamental and global problems, then we generate a new mentality. We need to help education, but not this education which ultimately leads to the impossibility of conceiving the most important problems" [7].

Transdisciplinarity, in turn, is an epistemological proposal according to the tenets of complexity that sees the advent of a human being capable of contending with all that is between, across, and beyond what has been considered Reality. To understand its broad scope, it is necessary to apply the methodology proposed by Basarab Nicolescu, whose three pillars are: levels of Reality (ontology), the included medium (logic), and complexity (epistemology). In the Manifesto of Transdisciplinarity, Nicolescu makes the contextualization of this approach and explains its broad scope [8]. Levels of perception are added to the levels of Reality. Nicolescu warns of dangers to the approach of recognizing only the levels of Reality but not the unknown the levels of perception, or vice versa.

The transdisciplinary perspective sees the human being as Homo sui trascedentalis, a person who is born again and whose potential "is inscribed in our very being" [8]. It is a being that is recognized in its irreducibility and its inner and outer double transcendence by which it accesses freedom. Transdisciplinarity does not comprehend the division between 
science and culture but is trans-cultural. This principle shows that human beings are identical from a spiritual point of view, beyond the vast difference between cultures.

In the building of Transdisciplinarity are the two great revolutions of the twentieth century: quantum physics and informatics. Quantum physics and informatics have paradoxically changed the face of the world. "Today, despite the unprecedented growth of knowledge in human history, we know more about what we do, and less about who we are" [8]. So our challenge is to work for self-knowledge, especially with the threat of spiritual destruction of the species by "the relentless logic of utilitarianism" and "efficiency and effectiveness" that fosters distorted phase techno-science.

Transdisciplinarity culture is a prerequisite for a transformation of mentalities. The true spirit of transdisciplinarity goes beyond what is being done now. It not only seeks the unification of knowledge but self-transformation and a new lifestyle.

In the field of education, transdisciplinarity is called to play a central role, first to imagine the revolution of intelligence based on balance between analytic intelligence, feelings, and body. Thus, a new type of education should take into account all dimensions of human beings.

\section{Results and Perspectives}

This is what has been attempted for more than five years at the Universidad Veracruzana in Mexico with a project named "Eco-dialogue Station" and today has become a Centre for Dialogue of Knowledge and Sustainability. Basarab Nicolescu knew this project in situ, and he certified its viability.

The purpose is to promote the transition from the Universidad Veracruzana to responsible and sustainable forms of knowledge and learning and research processes. Subsequently, the Master of Transdisciplinary Studies for Sustainability set the objective of building and ownership of a transdisciplinary approach to address real world issues from creativity, affection, wisdom, and dialogue of knowledges, which have generated action-based research projects.

But the examples are multiplied in various parts of the world, from Africa to Romania, from Mexico to Brazil, from Bolivia to Costa Rica and Chile, among others. Therefore experience has taught us that "an important evolution, such as move from a disciplinary to transdisciplinarity logic can not be so sudden and total" [9]. The transdisciplinarity approach should be implemented gradually and pragmatically. It is necessary to start with concrete situations and problems and analyze them from a transdisciplinary perspective.

Universities should encourage each student to develop a real and committed approach using multi-, inter-, and transdisciplinarity skills, enabling him or her to create in his/her professional life strategies to solve complex problems.

The University cannot fail to respond creatively to the demands of the labor market, social needs, and to one's own knowledge and new social relations. To better fulfill its mission, the University has to adapt to the cyber age, as Nicolescu described as a free zone [8].

The University must have a permanent training program for teachers aimed at achieving the "Transdisciplinarity attitude," i.e. the cosmic and conscious verticality driving the transdisciplinarity approach. A new transdisciplinarity culture requires a change of reference system, a prerequisite for a transformation of mentalities:

1. Shift from the consideration of a problem as if it depended on a single level of Reality and place in the field simultaneously different levels of Reality;

2. Renounce finding a solution to a problem in terms of "true" and "false" of the binary logic. Also, the solution to a problem cannot be more than temporary reconciliation of opposites, relikened at another level of Reality where contradictions are manifest;

3. Recognize the inherent complexity of the problem, namely the impossibility of decomposing the problem into simple, fundamental parts. Replacing the notion of foundation for consistency, in this multidimensional and multireferencial world.

The experience that I participated in the Veracruzana University confirmed the feasibility of Transdisciplinarity Research Workshops containing researchers from all disciplines. This refers to specific projects gradually introducing researchers and creators outside the University, including musicians, poets, and artists, working in different media and using new technologies with the aim of establishing academic dialogue between different cultural approaches, 
From a Disciplinary to a Transdisciplinary Vision of the University: A Space of Knowledge, Culture, Art, Spirituality, and Life

taking into account the inner experience and culture of the soul. This experience would broaden one's relationship with the world, with nature, and with others [10].

The University should be a space for discussion of the new university ethics. It requires rethinking ethics for universities from Latin America, an ethic that will not put the utilitarian or pragmatic principles ahead of social needs and human sentiments. How can the University surmount the two large living pressures today, the hyper-privatized by merchandising of knowledge and the hyper-public that demands a much larger public space?

According to Boaventura, it depends on the country project. Neo-liberalism in Mexico devastated the idea of a national project (which does not mean "nationalistic"). The country needs to redo it and remake the University. In a circular process, the nation and University will be reinventing each other at the same time.

How can we establish active, ongoing, systematic, and meaningful relations with all that live, a relationship that allows us to reach the full mental, emotional, physical, and spiritual potential that we have? The poet Michel Camus with his vertical gaze could see that the Transdisciplinarity University will emerge from the Multidisciplinary University, being the basis of this inner experience, which he called the "agriculture de l'âme," which only lives in self-creation and self-transformation oriented toward self-knowledge by both, teachers and students, who also must be unified and not viewed separately. This is not a "science of education, but an art of living, to create, transform and be reborn together in another way" [11].

It will be necessary to work on methods for awakening and recognizing the vertical levels of all kinds: perception, reality, complexity, nature and sense of language, silence, strength, and others. The spirit of inquiry cannot flourish otherwise. The University must re-introduce in all the domains of education dimensions of life and, as far as possible, of love. The University must meet the fundamental desires of the students: to enjoy physical and mental passion for research and pursue self-transformation.

Now that I have been away from the tendency to binary interpretation in a single level of Reality, I can not fail to recognize that establishing a link between thinking, doing, and feeling is necessary to learn simultaneously from different levels of Reality and go beyond that separation.

For this, I assert that for the University to become a multidimensional community requires a profound transformation toward transdisciplinarity, involving the ecologization and contextualization of knowledge.

The University should stand for, not against, what society demands. The University offerings should not be oriented to serve just a group of society, usually a minority, to the harm of a majority; hence the self-ethics and the communitarian ethic should be the basis of University education based in sustainable principles. This will achieve a genuine social transformation.

How can we reform the institution and not reform minds? And how can we reform minds without reforming the institution? There is no logical answer to this contradiction, Morin said, but life, he adds, "is capable of providing solutions to unsolvable problems logically" [12].

We must aspire to a University where effectivity and affectivity walk together, enabling human beings to manifest themselves in all their magnificence.

\section{References}

[1] Souza Santos, B., 2010. A Universidades no século XXI: para una reforma democrática e emancipatoria da Universidades.São Paulo. Cortez editora.

[2] Guillaumin, A., 2009. Suite para otra educación universitaria. In Guillaumn, Arturo y Octavio Ochoa (Eds.) Hacia otra educacin. Miradas desde la complejidad. Xalapa. Arana editores-Complexus.

[3] Ambrosio, U., 1997. El papel de las universidades en la sociedad moderna. Received from http://perso.club-internet.fr/nicol/ciret/, accessed: December, 10, 2010.

[4] Adame, D., 2009. Conocimiento y representacin

[5] Morin, E., 1994. Método III. El conocimiento del conocimiento. Madrid. Cátedra.

[6] Morin, E., 2000. Introducción al pensamiento complejo. Madrid. Gedisa.

[7] Carrizo, L., 2003. Conocimiento y Responsabilidad Social: Retos y Desafos hacia la Universidad Trans-diciplinaria. Received from http://artemisa.unbosque.edu.co/facultades/adminis tracion/revista/conocimyre-spons.pdf, accessed: July, 13, 2010. 
[8] Nicolescu, B., 2009. La Transdisciplinariedad, Manifiesto. Multiversidad Mundo Real Edgar Morin, A. C., Hermosillo.

[9] Galvani, P., 2007. Transdisciplinarit et cologisation dune formation universitaire: une pratique critique partir du paradigme de la complexit. Received from http://www.revueere.uqam.ca/PDF/Volume7/07_Galvani_P.pdf, accessed: January, 20, 2011.

[10] Nicolescu, B., 1997. Projet CIRET-UNESCO "Évo lution transdisciplinaire de l'Université". Received from http://basarab.nicolescu.perso.sfr.fr/ciret/locar no /locarno4.htm, accessed: November, 10, 2010.

[11] Camus, M., 1997. Quelle Universit pour demain? Received from http://perso.clubinternet.fr/nicol/ciret/, accessed: December, 10, 2010 .

[12] Morin, E., 2011. La Voie. Pour l'avenir de l'humanit. Paris. Fayard. Transdisciplinary Journal of Engineering \& Science, 2, pp.34-41.

\section{About the Author}

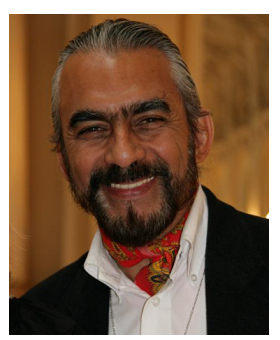

Dr. Domingo Adame Bachelor in Dramatic Literature and Theater by Autonomous National University of Mexico UNAM (1983), Master in Literary Studies by Autonomous University of Mexico State (1993) and PhD by Iberoamericana University (2001), has followed a course of specialization in performance and theatrical direction in Theater School of Krakow, Poland (1985-86). He has worked as actor, director, professor and theatrical researcher in several institutions of higher education of the country. From 2001 is professor-researcher in Veracruzana University in Xalapa, Mexico.

Is author, between other titles of: The theatrical director interpreter- creator. Proceed hermeneutic having to the dramatic text (1995); Theaters and Theatricalities in Mexico, XX Century (2003); Tribute of the Oxymoron. Introduction in the Theories of the Theatricality (2005); To Comprise the Theatricality (2007) and Knowledge and Representation. A re-learning to the Trans- Theatricality (2009).
It has been director of the magazine The LatinAmerican Scene of The International Institute of Theory and Critical of Latin-American Theater (1992-1995) and is Editor of the Magazine Theatrical Research of The Mexican Association of Theater Research.

Has been Director of the National Centre of Theatrical Research Rodolfo Usigli of The National Institute of Fine Arts (1989-1993), Chair of the Arts Department of The Americas University in Puebla (1994-1996), General Coordinator of The National Association of TheaterCommunity (1986-1988), Founder President of Mexican Association of Theater Research, and Director of the Theater Faculty of The Veracruzana University (2005-2009).

His lines of Research are Theater in Mexico, theatrical Theory and Culture, Complexity and Transdisciplinarity. He is member of the National System of Researchers by the National Council of Science and Technology (CONACYT).

Copyright (c) 2011 by the author. This is an open access article distributed under the Creative Commons Attribution License (https://creativecommons.org/licenses/by/4.0/), which permits unrestricted use, distribution, and reproduction in any medium, provided the original work is properly cited. 